\title{
On the Global Ambitions of Phenomenal Conservatism
}

What is the role of phenomenal consciousness in grounding epistemic justification? This paper explores the prospects for a global version of phenomenal conservatism inspired by the work of Michael Huemer, which says that all epistemic justification is grounded in phenomenal seemings. I'm interested in this view because of its global ambitions: it seeks to explain all epistemic justification in terms of a single epistemic principle. According to this global principle of phenomenal conservatism, you have epistemic justification to believe whatever seems to you strongly enough on balance to be true. ${ }^{1}$

One of the attractions of phenomenal conservatism is that it offers such a simple and unified framework for explaining the epistemic role of phenomenal consciousness. I will argue, however, that the simplicity of phenomenal conservatism is not a theoretical virtue, but a theoretical vice, since it distorts the epistemological phenomena it is supposed to explain. In effect, phenomenal conservatism seeks to explain all epistemic justification on the same model as perception. But this has the predictable effect of distorting the epistemology of other domains, including introspection, inference, and a priori justification.

This paper argues against phenomenal conservatism on two distinct fronts. First, it gives an overly restrictive account of the nature of evidence: it says that all evidence consists of phenomenal facts about how things seem. And second, it gives an overly simplified account of the nature of the evidential support relation: it says that a proposition is supported by your evidence just in case it seems strongly enough on balance to be true. If we relax these restrictions on evidence, or we build more structure into the evidential support relation, then we must abandon the global ambitions of phenomenal conservatism.

This paper has a positive aim as well as a negative one: I argue that we should replace phenomenal conservatism with phenomenal accessibilism. Phenomenal accessibilism combines accessibilism with a phenomenal conception of evidence. This view diverges from phenomenal conservatism in two ways. First, it builds more structure into the evidential support relation: accessibilism says that your evidence is always self-evident. And second, it yields a more liberal version of the phenomenal conception of evidence: it says that your evidence includes not just the phenomenal facts about how things seem, but all the phenomenally individuated facts about your current mental states. ${ }^{2}$

There is an important connection between these two points. Accessibilism provides the best theoretical motivation for endorsing the phenomenal conception of evidence in the first place. The main problem with phenomenal conservatism is that both its account of evidence and its account of the evidential support relation are in tension with accessibilism. Phenomenal conservatism is therefore self-defeating in the sense that it undermines its own

\footnotetext{
${ }^{1}$ See Huemer (2001: Ch. 5) for his original defense of phenomenal conservatism. Others who defend similar views include Tucker (2010), Brogaard (2013), Chudnoff (2013), and Bengson (2015), although these authors make no explicit commitment to the fully global version of phenomenal conservatism.

${ }^{2}$ See Smithies (2019) for a more extended defense of phenomenal accessibilism.
} 
best motivation. Phenomenal accessibilism provides a more attractive theoretical framework for explaining the epistemic role of consciousness.

\section{Phenomenal Conservatism}

In the course of defending moderate foundationalism about perceptual knowledge, Michael Huemer proposes the following principle of phenomenal conservatism:

If it seems to $\mathrm{S}$ as if $p$, then $\mathrm{S}$ thereby has at least prima facie justification for believing that $p$. (2001: 99)

This is a principle about foundational - that is, immediate or non-inferential - justification. It says that seemings are sufficient to give you non-inferential justification: necessarily, if it seems to you that $p$, then you thereby have at least some degree of defeasible, non-inferential justification to believe that $p$. How much justification you have depends on the strength of your seemings, since the degree of justification provided by a seeming is proportional to its strength. According to Huemer, there are no restrictions on which seemings can play this foundational epistemic role.

Huemer (2001: 99) makes the further claim that the principle of phenomenal conservatism is the only principle of foundational justification. On this view, seemings are necessary as well as sufficient for giving you foundational justification: necessarily, if you have some degree of defeasible, non-inferential justification to believe that $p$, then this is because it seems to you that $p$. Huemer (2001: 100) draws the corollary that only seemings can defeat the foundational justification provided by other seemings. When your seemings come into conflict, your degree of justification to believe a proposition depends solely on the relative strengths of your conflicting seemings. Hence, all foundational justification has its source in seemings alone.

In more recent work, Huemer (2016) extends phenomenal conservatism from foundational to non-foundational - that is, from non-inferential to inferential - justification. On this view, all inferential justification has its source in inferential seemings. You have epistemic justification to infer a conclusion from some premises just when and because the following conditions hold in the absence of defeaters: (i) the premises seem true, (ii) the conclusion seems to follow either deductively or inductively from the premises, and (iii) the conclusion thereby seems true. ${ }^{3}$

Putting all these claims together, we arrive at the following global principle of phenomenal conservatism:

\footnotetext{
${ }^{3}$ Huemer (2016) focuses on doxastic justification, but it's implausible that inferential seemings are required for doxastic justification unless they are required for propositional justification too. Moreover, denying this would be a significant departure from the global ambitions of phenomenal conservatism. In any case, much of my discussion applies to a nearly global form of phenomenal conservatism that is restricted to foundational sources of propositional justification, although I believe this view has no stable motivation.
} 
Necessarily, you have epistemic justification to believe that $p$ just when and because it seems to you strongly enough on balance that $p$.

The suggestion is that we can explain all epistemic justification in terms of a single unifying principle: you should always believe whatever seems strongly enough on balance to be true. This means that epistemic justification supervenes on seemings: there can be no difference in which propositions you have epistemic justification to believe without some difference in which propositions seem true. It also means that all epistemic justification is grounded in seemings: every epistemic fact about which propositions you have justification to believe is grounded in some non-epistemic fact about which propositions seem true. All of these claims are concerned with epistemic justification in the propositional sense, rather than the doxastic sense. ${ }^{4}$

The term 'phenomenal conservatism' is used in many different ways, but I'll use it to refer to the view that endorses all three of the following claims:

(1) Weak Phenomenal Conservatism. Seemings are sufficient for epistemic justification: necessarily, if it seems to you that $p$, then you thereby have some degree of defeasible epistemic justification to believe that $p$.

(2) Strong Phenomenal Conservatism. Seemings are necessary for epistemic justification: necessarily, if you have some degree of defeasible epistemic justification to believe that $p$, then this is because it seems to you that $p$.

(3) Global Phenomenal Conservatism. All epistemic justification is grounded in seemings: necessarily, you have sufficient epistemic justification to believe that $p$ just when and because it seems to you strongly enough on balance that $p$.

My own view is partially concessive to phenomenal conservatism: I accept the weak principle, although I reject the strong and global principles. To that extent, I make a much greater concession to phenomenal conservatism than many other critics of the view. ${ }^{5}$

Phenomenal conservatism can be situated within the more general framework of evidentialism. Evidentialism is the thesis that you have epistemic justification to believe whatever is supported strongly enough by your evidence. Any specific version of evidentialism needs two things: (i) an account of the nature of evidence, and (ii) an account of the nature of the evidential support relation. ${ }^{6}$

\footnotetext{
${ }^{4}$ Huemer (2006: 151) explicitly endorses the supervenience thesis. I cannot find an explicit statement of the grounding thesis, but it is very much in the spirit of Huemer's view. ${ }^{5}$ See Hawthorne and Lasonen-Aarnio (forthcoming) for a more radical critique of phenomenal conservatism that abandons the phenomenal conception of evidence altogether. ${ }^{6}$ See Feldman and Conee (1985) and Smithies (2019: Ch. 6) on evidentialism. Huemer (2018) criticizes evidentialism, but his critique neglects one of the main points of this paper, which is that epistemic justification is not wholly grounded in evidence, but partially in facts about the evidential support relation.
} 
The evidentialist version of phenomenal conservatism yields an especially strong version of the phenomenal conception of evidence: it says that your evidence includes all and only the phenomenal facts about how things seem to you. Moreover, it combines this account of evidence with a simple account of the evidential support relation: your evidence supports a proposition to the extent that it seems on balance to be true; that is, the more strongly it seems true, the more strongly it is supported by your evidence. This version of evidentialism implies the global principle of phenomenal conservatism, which says that you have epistemic justification to believe whatever seems strongly enough on balance to be true.

Phenomenal conservatism certainly has its attractions. First, as I've noted, it offers a simple and unified epistemological framework that promises to subsume all epistemic justification under a single epistemic principle. Second, it offers an attractive framework for explaining the epistemic significance of phenomenal consciousness. And, third, it promises to explain so-called "internalist intuitions" about epistemic justification in cases of envatment and demonic deception, clairvoyance and super-blindsight, and so on. Ultimately, however, I'll argue that the global ambitions of phenomenal conservatism cannot succeed.

There are serious problems both with its account of evidence and the evidential support relation. First, its version of the phenomenal conception of evidence is much too restrictive, since it says that only seemings can be evidence. Accessibilism provides no motivation for this restriction, since all phenomenal facts are self-evident, and not just the phenomenal facts about how things seem. Moreover, this restriction generates problems for the epistemology of introspection and memory. There is some pressure to avoid these problems by accepting a diachronic version of phenomenal conservatism, but this conflicts with accessibilism, which provides the best motivation for endorsing the phenomenal conception of evidence in the first place. Hence, phenomenal conservatism threatens to undercut its own best motivation.

Second, the global ambitions of phenomenal conservatism depend on an overly simplified account of the evidential support relation. This account distorts the epistemology of introspection, logic, and inference by subsuming them under the same model as perception. Perception is a bad model for these other domains because there are structural dimensions of epistemic rationality that have no analogue in perception. One instance of this general problem is that phenomenal conservatism cannot solve what Huemer (2011) calls "the puzzle of meta-coherence": in other words, it cannot explain why epistemic rationality requires meta-coherence. This is because its account of the evidential support relation is incompatible with accessibilism. Once again, this threatens to undermine the motivations for accepting the phenomenal conception of evidence in the first place.

My own view, phenomenal accessibilism, diverges from phenomenal conservatism both in its account of evidence and its account of the evidential support relation. First, I endorse a more liberal version of the phenomenal conception of evidence. On this view, your evidence includes not just the phenomenal facts about how things seem, but all the phenomenal facts about your experience, and all the phenomenally individuated facts about your beliefs, desires, and other standing attitudes. Second, I endorse a version of accessibilism that builds more structure into its account of the evidential support relation. There are structural constraints on which propositions I can have epistemic justification to believe, which are explained by necessary facts about the evidential support relation, rather 
than contingent facts about my evidence. Contrary to phenomenal conservatism, it doesn't always make any difference whether a proposition seems true.

My central claim is that the global ambitions of phenomenal conservatism are incompatible with accessibilism. At the same time, accessibilism provides the best theoretical motivation for endorsing the phenomenal conception of evidence in the first place. I therefore conclude that we cannot explain the epistemic significance of phenomenal consciousness within the framework of phenomenal conservatism. We need to adopt the framework of phenomenal accessibilism instead.

Here is the plan for this paper. Having defined phenomenal conservatism (section 1), I'll clarify the central concept of "seemings" (section 2). Next, I'll criticize its account of the nature of evidence (section 3) and its account of the evidential support relation (section 4). Finally, I'll explain how phenomenal accessibilism avoids these problems (section 5) and I'll end with some more general conclusions (section 6).

\section{Seemings}

What are seemings? We need to answer this question before we can understand exactly what phenomenal conservatism is saying. In Huemer's (2001) foundationalist account of perceptual knowledge, perceptual experiences are the paradigmatic examples of seemings. At the same time, however, Huemer claims that there are many other kinds of seemings, including introspective seemings, intellectual seemings, and inferential seemings. What do all these different kinds of seemings have in common?

Following Huemer's (2001: 65-79) discussion of perceptual experience, I'll assume that all seemings have three essential features: (i) phenomenal character, (ii) representational content, and (iii) forcefulness. First, seemings have phenomenal character: there is something it is like for you when things seem a certain way. Second, seemings have representational content: when things seem a certain way, you thereby represent the world as being that way; indeed, you sometimes misrepresent the world, when things are not the way they seem. Third, seemings represent their contents with a distinctive kind of force, which Huemer (2001: 77-79) calls "forcefulness". The forcefulness of seemings is what sets them apart from other experiences with representational content, including imaginative experiences of visualization and cognitive experiences of judgment.

What Huemer means by the "forcefulness" of perceptual experience is what I mean, and what others mean, by "presentational force". ${ }^{7}$ These are different labels for the distinctive phenomenal character of perceptual experience in virtue of which it plays its distinctive epistemic role. It is only because perceptual experience represents its content with presentational force that it can justify believing its content without standing in need of justification. The presentational force of perceptual experience explains the phenomenal contrast between seeing that $p$ and merely visualizing that $p$ or judging that $p$. Moreover, it explains why seeing that $p$ plays a distinctive epistemic role that cannot be played by

\footnotetext{
${ }^{7}$ My own view is presented in Smithies (2019: Ch. 3), but see also Chudnoff (2013) and Bengson (2015) for further discussion of presentational phenomenology.
} 
visualizing that $p$ or judging that $p$. This is because seeing that $p$ involves a perceptual experience in which you represent that $p$ with presentational force. Visualizing that $p$ or judging that $p$ cannot play the same epistemic role because these imaginative and cognitive experiences don't represent their contents with presentational force.

Presentational force - like phenomenal consciousness in general - cannot be defined in more basic terms, but only by example and contrast. It is the kind of phenomenal character that distinguishes the perceptual experience of seeing that $p$ from an imaginative experience of visualizing that $p$ or a cognitive experience of judging that $p$. Huemer introduces the notion of forcefulness in much the same way. He occasionally lapses into explaining forcefulness in terms of how things seem: for example, "it is the fact that, in the experience, it seems to one that something satisfying the content of the experience actually exists, here and now" (2001: 79). This is problematic because you could imagine or judge this proposition without thereby representing it forcefully. Of course, these experiences are not seemings, but this only goes to show that we cannot define seemings in terms of the representation of distinctive contents. Just as the name suggests, forcefulness is a distinctive kind of representational force, rather than a distinctive kind of representational content.

I've argued elsewhere that the phenomenal character of perceptual experience can be explained within the more general framework of representationalism. ${ }^{8}$ On this view, the phenomenal character of perceptual experience is identical with a way of representing content with presentational force. This representationalist theory of perceptual experience can be combined with the weak principle of phenomenal conservatism, which says that if you have an experience that represents some content with presentational force, then you thereby have defeasible, non-inferential justification to believe that content. It follows that perceptual experience justifies believing some content in virtue of its phenomenal character alone. Hence, phenomenal conservatism provides an attractive framework for explaining the role of phenomenal consciousness in the epistemology of perception.

It's worth noting that Huemer rejects representationalism: he writes, "I view qualia as something over and above representational content" (2001: 67). On this view, the phenomenal and representational properties of perceptual experience are distinct and merely contingently connected with each other. As Huemer notes, however, this threatens to undermine the idea that the phenomenal character of perceptual experience has any essential role to play in explaining our knowledge of the external world:

If indeed the quale of a perceptual experience is something beyond its representational content, and if the function of perceptual experiences is purely assertive (that is, their function is just to give us information about the world), what, if anything, are qualia good for? Is there any biological reason why we should have experiences with qualia, rather than just having experiences with representational contents and no qualia? (2001: 70)

\footnotetext{
${ }^{8}$ See Smithies (2019: Chs. 2 and 3) for further discussion of representationalism and its application to the epistemology of perception.
} 
To rephrase the question: is there any reason why phenomenal consciousness should be needed for acquiring knowledge or epistemically justified belief about the external world? Huemer gives no answer that would explain why unconscious perceptual information in super-blindsight cannot provide knowledge of the external world. In fact, he explicitly mentions super-blindsight and says, "this sort of qualia-lacking awareness plays the same sort of role in our knowledge of the external world as the more typical perceptual experiences" (2001: 67; cf. 89 n. 30).

In order to do justice to the role of phenomenal consciousness in the epistemology of perception, we need to combine weak phenomenal conservatism with representationalism. On this view, the phenomenal character of perceptual experience just is a way of representing contents about the external world with presentational force. Unconscious perceptual states can have representational properties too, but they cannot have exactly the same representational properties as perceptual experience. In particular, they cannot represent contents with the same kind of presentational force as perceptual experience.

Chris Tucker (2010: 530-531) argues that there are weak seemings in blindsight, which explain why subjects make reliable guesses about the blind field. These seemings are explained in terms of feelings of assertiveness, which "make it feel as though the seeming is 'recommending' its propositional content as true or 'assuring' us of the content's truth" (2010: 530). But this characterization fails to distinguish perceptual experiences of seeing from cognitive experiences of judgment. After all, judgment assertively represents its content in the sense that it "recommends" or "assures" that its content is true, but it cannot play the distinctive epistemic role of perception in justifying beliefs without standing in need of justification. Perhaps blindsighted subjects have cognitive experiences - hunches, if you like - that assertively represent propositions about the blind field with a low degree of strength. Nevertheless, these cognitive experiences cannot play the distinctive epistemic role of perceptual experience, since they don't represent their contents with the right kind of presentational force.

The weak principle of phenomenal conservatism provides an attractive framework for explaining the role of phenomenal consciousness in the epistemology of perception. I'll argue that the strong and global principles, in contrast, distort the epistemic role of phenomenal consciousness in other domains, including introspection, inference, and a priori justification. As I've noted, Huemer claims that we have not only perceptual seemings, but also introspective, intellectual, and inferential seemings. Indeed, the plausibility of strong phenomenal conservatism depends on this claim; otherwise, we don't have enough seemings to explain how beliefs are justified by introspection, intuition, and inference. In this paper, I'll argue that we have no good reason to believe this claim. In my view, there are no nonperceptual seemings: only perceptual experiences and perceptual memories represent their contents with presentational force. ${ }^{10}$

\footnotetext{
${ }^{9}$ Compare Chudnoff (2013: 30) and Bengson (2015: 719) for the view that there are no seemings in blindsight as characterized in terms of presentational force.

${ }^{10}$ Huemer (2001: 99) claims that we have memory-related seemings in factual memory as well as perceptual memory, whereas I accept only the latter.
} 
I'm not denying that we have intellectual, introspective, or inferential experiences that we might report by saying, "It seems to me that $p$ ". The problem is that our ordinary use of the term 'seems' is not a good guide to seemings in Huemer's technical sense. For example, when I judge that $p$, it's perfectly natural to say that it seems to me that $p$, and yet judgments are not seemings in this sense. This point is crucial for Huemer's purposes, since he denies that judgments can play the same epistemic role as perceptual experience in justifying beliefs without standing in need of justification. This is precisely because the experience of judgment does not represent its content with the right kind of presentational force: it is assertive, but not presentational.

I'm not disputing that we have intellectual, introspective, and inferential experiences that assertively represent their contents, but I deny that they have the right kind of forcefulness to justify belief without standing in need of justification. That is not to say that these experiences are reducible to judgments, or inclinations towards judgment, or feelings of confidence, or anything else. I remain agnostic about this. Even if some of these experiences are sui generis, and hence irreducible to more familiar categories, it doesn't follow that they have the right kind of phenomenal character to justify belief without standing in need of justification. This further claim is what I am denying.

The question in dispute is whether introspective, intellectual, and inferential experiences have the same kind of phenomenal character as perceptual experiences: the kind that suits an experience to justify beliefs without standing in need of justification. How can we resolve this dispute? As we've seen, ordinary language is too blunt an instrument, since our use of the word 'seems' doesn't track seemings in Huemer's technical sense. ${ }^{11}$ Moreover, the dispute cannot be resolved solely by appeal to introspection. Both sides can agree that there are phenomenal similarities and differences between perception and intuition: for example, both are assertive, but only perception is sensory. The question remains whether these experiences are similar enough, and in the right ways, to play the same kind of epistemic role. That is not a question that can be resolved by introspection alone.

Instead, the dispute must be resolved on epistemological grounds. What are the epistemological consequences of assuming that we have introspective, intellectual, and inferential seemings that play the same kind of epistemic role as our perceptual seemings? I'll argue that this assumption, when combined with weak phenomenal conservatism, yields implausible epistemological consequences. Since weak phenomenal conservatism is true, I'll conclude that the assumption is false: we have no introspective, intellectual, or inferential seemings. This is bad news for strong and global versions of phenomenal conservatism. My epistemological argument against phenomenal conservatism has two parts: I criticize its account of evidence in section 3 and its account of evidential support in section 4 .

${ }^{11}$ Compare Siegel and Byrne (2018) for skepticism about the prospects of resolving debates about the contents of perception by appealing to ordinary language considerations. Hawthorne and Lasonen-Aarnio (MS) argue that the semantics of 'seems' locutions provides no empirical support for the existence of seemings in Huemer's technical sense. 


\section{Problems about Evidence}

What does phenomenal conservatism imply about the nature of evidence when it is combined with the more general framework of evidentialism? The answer is that it yields a strong version of the phenomenal conception of evidence, which says that your evidence includes all and only the phenomenal facts about how things seem. Phenomenal conservatism says these are the only facts that can make a difference to which propositions you have epistemic justification to believe. In other words, your evidence is exhausted by how things seem.

As Huemer (2006) argues, one advantage of phenomenal conservatism is that it explains so-called "internalist intuitions" about epistemic justification in cases of envatment and deception, clairvoyance and super-blindsight. Any phenomenal duplicate of yours who is deceived by an evil demon or an evil neuroscientist has epistemic justification to form all the same beliefs on the basis of perceptual experience. This is because things seem exactly the same way to each of you: your perceptual experience represents the same phenomenal contents with the same degree of presentational force. In contrast, subjects with clairvoyance or super-blindsight don't have epistemic justification to form beliefs on the basis of unconscious perceptual information. This is because the information in question is not represented with the distinctive phenomenal character of perceptual experience: there are no seemings in clairvoyance or super-blindsight. ${ }^{12}$

Despite this, I'll argue that we should reject phenomenal conservatism because its phenomenal conception of evidence is much too restrictive. All seemings are evidence, but not all evidence is seemings. Your evidence includes not just phenomenal facts about how things seem, but all the phenomenal facts about your experience. Moreover, your evidence includes all the phenomenally individuated facts about your mental states, including your beliefs, desires, and other standing attitudes. We should endorse a more liberal version of the phenomenal conception of evidence which says that your evidence includes all the phenomenally individuated facts about your current mental states. This view fits better with the motivations for accepting the phenomenal conception of evidence in the first place. ${ }^{13}$

There is no principled motivation for restricting evidence to phenomenal facts about how things seem. We don't need this restriction in order to explain internalist intuitions about cases. All we need is the claim that perceptual seemings are present in your envatted counterparts and absent in your clairvoyant counterparts. The restriction of evidence to seemings is not justified by internalist intuitions alone, but only by the further appeal to theoretical simplicity. As I'll explain, however, the appeal to theoretical simplicity results in epistemological distortion: we cannot explain the epistemology of introspection or memory on the same model as perception.

\footnotetext{
${ }^{12}$ Huemer (2006) construes clairvoyance as an alien form of perceptual experience, rather than a version of super-blindsight. I agree that this kind of clairvoyance provides defeasible justification, although it may be defeated by evidence of unreliability.

${ }^{13}$ See Smithies (2019: Ch. 6) for this version of the phenomenal conception of evidence and its application to the internalist intuitions. See also Smithies (2019: Ch. 4) for the argument that beliefs and other standing attitudes are individuated by their phenomenal dispositions.
} 
Moreover, the restriction to seemings is not motivated by accessibilism about epistemic justification. Accessibilism says that epistemic justification is "luminous" in the sense that you're always in a position to know which propositions you have epistemic justification to believe. This provides a principled argument for the phenomenal conception of evidence: epistemic justification is luminous only if your evidence is luminous, but your evidence is luminous only if the phenomenal conception of evidence is true. However, this argument supplies no motivation for restricting evidence to seemings. This is because the luminous facts about your mental states include not just the phenomenal facts about how things seem, but all the phenomenal facts about your experience, and all the phenomenally individuated facts about your beliefs, desires, and other standing attitudes. Hence, accessibilism motivates a more liberal version of the phenomenal conception of evidence, which includes all of these facts within your evidence. ${ }^{14}$

Restricting evidence to seemings is not only unmotivated, but also implausible. The benefits of theoretical simplicity are outweighed by the costs of epistemological distortion. This becomes apparent when we shift our focus from perception to introspection. A central insight of phenomenal conservatism is that experience justifies believing its content only if it represents its content with presentational force. This is why perceptual experience justifies believing its content, while imaginative experience does not. Presentational force is necessary for an experience to justify believing its content, but how far does this point extend? Does an experience also need presentational force in order to justify the introspective belief that you have that very experience?

The "simple theory" of introspection says no: whenever you have an experience, you thereby have introspective evidence that puts you in a position to know that you have that very experience. Seemings are not unique in this regard, since all experiences are introspectively luminous in just the same way. This includes not only perceptual experiences of seeing, but also imaginative experiences of visualizing, cognitive experiences of judging, affective experiences of desiring, and so on. All seemings are experiences, but not all experiences are seemings. My introspective evidence includes not just the phenomenal facts about how things seem, but all the phenomenal facts about my experience. ${ }^{15}$

To block this objection, phenomenal conservatism needs to embrace a perceptual model of introspection. On the perceptual model, your introspective evidence is not constituted by facts about your experience, but rather by facts about how your experience introspectively seems to you. These introspective seemings mediate between the experiential facts and introspective beliefs in the same way that perceptual seemings mediate between external facts and perceptual beliefs. Just as your belief that you have hands is justified by the perceptual seeming that you have hands, so your belief that it perceptually seems that you have hands is justified by the introspective seeming that it perceptually seems that you have hands. This is what a global form of phenomenal conservatism needs to say. But do we

\footnotetext{
${ }^{14}$ See Smithies (2019: Ch. 7) for the argument that accessibilism requires commitment to the phenomenal conception of evidence.

${ }^{15}$ See Smithies (2019: Ch. 5) for a defense of the simple theory of introspection and Smithies (2019: Ch. 11) for a reply to Williamson's (2000: Ch. 4) anti-luminosity argument.
} 
really have introspective seemings that mediate between our perceptual seemings and our introspective beliefs about them? This claim is hard to defend.

To undermine the perceptual model of introspection, Sydney Shoemaker invites us to conduct a first-person experiment:

Raise both your hands before you, about a foot apart and a foot in front of your face. Now perform the following two attention shifts. First, shift your attention from one hand to the other. Second, shift your attention from your visual experience of the one hand to your visual experience of the other. Do you do anything different in the second case than in the first? (1996: 219)

As Shoemaker correctly notes, the only thing that changes in the second case is which aspect of your visual experience you're thinking about. In the first case, we can explain which hand you're thinking about by appealing to the focus of perceptual attention. Shifting perceptual attention from one hand to the other explains why you think about one hand and then other. In the second case, in contrast, we cannot explain which experience you're thinking about by appealing to the focus of introspective attention. This is because shifting introspective attention from one experience to another, where this is something distinct from merely shifting perceptual attention from one hand to the other, is just a matter of thinking about one experience and then the other.

Shoemaker's point reflects a fundamental difference between perception and introspection. Perceptual attention to an object is more primitive than thought about an object and so it can explain which objects you're thinking about. In contrast, introspective attention to your own experience is just a matter of thinking about your own experience and so it cannot explain which experiences you're thinking about. In perception, your ability to think about the external world is mediated by a more primitive form of perceptual representation of the external world. In introspection, in contrast, your ability to think about your own experience is not mediated by a more primitive form of introspective representation of your own experience. Introspective knowledge is not based on introspective awareness of your own experience in the same way that perceptual knowledge is based on perceptual awareness of the external world. To my mind, this is Shoemaker's most powerful criticism of the perceptual model of introspection.

We should reject the perceptual theory of introspection and replace it with the simple theory. Your introspective evidence consists not in facts about how your experience seems to you, but rather in facts about how your experience really is. On the simple theory, there is no motivation for restricting your introspective evidence to phenomenal facts about how things seem. It includes all the phenomenal facts about your experience and all the phenomenally individuated facts about your beliefs, desires, and other standing attitudes. Introspection puts you in a position to know not only what experiences you have, but also what you believe. If you believe that $p$, for example, then you thereby have introspective evidence that puts you in a position to know that you believe that $p$. This motivates a more 
liberal version of the phenomenal conception, according to which your evidence includes all the phenomenally individuated facts about your current mental states. ${ }^{16}$

There is another reason for endorsing a version of the phenomenal conception that is liberal enough to include facts about what you believe within your evidence. Otherwise, it is hard to account for the epistemic role that beliefs play in justifying other beliefs. Any version of evidentialism that restricts your evidence to facts about your experience faces the following barrage of problems:

(1) The problem of stored beliefs: What justifies my belief that my name is NN when I'm thinking about other things?

(2) The problem of forgotten evidence: What justifies my belief that Washington DC is the capital of the US when I cannot remember how I originally formed my belief?

(3) The problem of stored defeaters: What explains why I lack justification to believe your prediction that I can complete the hike to Precarious Peak when I'm temporarily unable to access my knowledge that you've been unreliable in the past?

(4) The problem of background beliefs: What explains the difference in epistemic justification between an expert and novice birdwatcher when they both see a spotted flycatcher, and it seems the same way to both of them, but only the expert knows that spotted flycatchers look this way?

We can solve these problems by endorsing a principle of doxastic conservatism, which says that if you believe that $p$, then you thereby have some degree of defeasible justification to believe that $p$. This contradicts strong phenomenal conservatism, however, according to which phenomenal seemings are the only source of justification. ${ }^{17}$

How can proponents of strong phenomenal conservatism solve these problems? There is some pressure to endorse a diachronic version of phenomenal conservatism, which says that what you have epistemic justification to believe now depends not just on what seems true now, but also on what seemed true in the past. On this view, we can avoid the problems for synchronic versions of phenomenal conservatism by appealing to facts about how things seemed in the past, rather than facts about what you believe in the present. ${ }^{18}$

Huemer (1999) endorses a diachronic version of phenomenal conservatism in response to the problem of forgotten evidence. On this view, beliefs stored in memory can

\footnotetext{
${ }^{16}$ See Smithies (2019: Ch. 5) for arguments that we need to extend the simple theory of introspection from conscious experience to standing belief.

${ }^{17}$ See Smithies (2019: Ch. 4) for further discussion of doxastic conservatism and its role in solving these problems. See also Harman (1986: Ch. 3) and McGrath (2007) for more extensive discussion of the problem of forgotten evidence.

${ }^{18}$ This view is hard to reconcile with evidentialism. How can your current evidence include facts about the past that you're no longer in a position to know? And if you no longer have this evidence, then how can it affect what you have epistemic justification to believe?
} 
be justified now in virtue of historical facts about how they were formed and maintained in the past. This means that beliefs can transmit the justificatory force of seemings from the past to the present. If on Monday I form a justified belief on the basis of how things seem, and I retain my belief until Friday, then I still have justification to hold the belief on Friday, even if I've forgotten how things seemed to me on Monday. And yet the same doesn't apply to someone who is my phenomenal duplicate on Friday, but whose belief was unjustified when it was formed on Monday. Huemer writes:

The one person must be counted justified in his present belief (else we have memory skepticism), and the other must be counted unjustified (else we have an unjustified belief converted to a justified belief by the passage of time). It follows that the justificatory status of the belief . . does not supervene on the current, intrinsic state of the believer. (1999: 352)

Doxastic justification is not determined synchronically, of course, since causal relations of proper basing are often diachronic. Huemer is making the more interesting and controversial claim that propositional justification is not determined synchronically, since intrinsic duplicates can differ in which propositions they have epistemic justification to believe owing to differences in how their beliefs were formed and maintained in the past.

This diachronic version of phenomenal conservatism conflicts with the natural reading of Huemer's characterization of the internalist intuition about epistemic justification:

There cannot be a pair of cases in which everything seems to a subject to be the same in all epistemically relevant respects, and yet the subject ought, rationally, to take different doxastic attitudes in the two cases - for instance, in one case to affirm a proposition and in the other to withhold. (2006: 151)

On a diachronic version of phenomenal conservatism, epistemic justification doesn't supervene on how things seem now, but merely on the total history of how things seem. In fact, Huemer's position conflicts with this historical version of the supervenience thesis too: he holds that etiological facts about the formation and maintenance of your beliefs can determine whether the justificatory force of past seemings are transmitted to the present, but these etiological facts are not guaranteed to impact how things seem either in the past or in the present.

A more fundamental problem is that the diachronic version of phenomenal conservatism is incompatible with accessibilism. It implies that you're not always in a position to know which propositions you have justification to believe, since you're not always in a position to know how things seemed in the past. Which propositions you have justification to believe now depends on facts about your history that are not luminous to you in the present. According to Huemer, my phenomenal duplicate and I have justification to believe different propositions on Friday owing to differences in how things seemed on Monday. After a busy week, however, neither of us is in a position to recall how things seemed on Monday. As a result, we're not always in a position to know which propositions we have justification to believe at any given time. 
One potential reaction is to reject accessibilism, but this has some implausible consequences. ${ }^{19}$ Suppose my phenomenal duplicate has justification to believe that $p$, whereas I have justification to disbelieve that $p$, owing to some difference in our causal history. Nevertheless, my phenomenal duplicate is not in a position to know that he has justification to believe that $p$. On the contrary, it seems to him, just as it seems to me, that he has justification to disbelieve that $p$. So, in the absence of defeaters, he has justification to hold an akratic or meta-incoherent combination of doxastic attitudes: namely, believing that $p$, while believing that he lacks justification to believe that $p$, and believing instead that he has justification to disbelieve that $p$. Intuitively, however, this kind of meta-incoherence is always epistemically irrational. Indeed, Huemer agrees: "If you hold on to your first-order belief while simultaneously denying that it constitutes knowledge, then you are guilty of some sort of irrationality" (2011: 1).

Another implausible consequence is that my phenomenal duplicate has justification to hold a belief that cannot survive a justified process of critical reflection. After all, he has justification to believe that $p$, but he is not in a position to know that he has justification to believe that $p$, since it seems to him on reflection that he has justification to disbelieve that $p$. But it is quite implausible that anyone can have justification to hold a belief that cannot survive justified reflection. Again, Huemer agrees: "A rational person, it seems, ought to be in a position, if he comes to reflect on his doxastic attitudes . . to approve those attitudes as justified" (2006: 154).

A more general problem is that rejecting accessibilism is self-defeating in the sense that it undercuts the best motivation for phenomenal conservatism. After all, accessibilism provides the best motivation for endorsing the phenomenal conception of evidence in the first place. We cannot fall back on the claim that it's motivated by internalist intuitions about cases. After all, these internalist intuitions need to be supported with principled theoretical arguments if they are to withstand the test of reflective equilibrium. Moreover, the best theoretical arguments for these internalist intuitions appeal to accessibilism.

Can the diachronic version of phenomenal conservatism be reconciled with accessibilism? In section 4.3, I'll examine Huemer's (2011) solution to what he calls "the puzzle of meta-coherence". He argues that higher-order justification to believe that you lack justification to believe that $p$ defeats your first-order justification to believe that $p$. Similarly, he might say, higher-order justification to believe that you have justification to believe that $p$ gives you justification to believe that $p$. If so, then perhaps my phenomenal duplicate and I have justification to believe the same propositions on Friday, despite the historical differences between us. I'll criticize this solution in due course, but the point to make now is that it cannot succeed in full generality without undermining the diachronic version of phenomenal conservatism. If your past seemings are always trumped by how things presently seem about your past seemings, then they never make a justificational difference. We are stuck with the synchronic version of phenomenal conservatism and all its associated problems.

${ }^{19}$ See Smithies (2019: Chs. 7 \& 8) for these arguments for accessibilism. 
In conclusion, we should reject phenomenal conservatism because it imposes implausible restrictions on our evidence. All seemings are evidence, but not all evidence is seemings. To insist otherwise is implausible, since it distorts the epistemology of introspection and memory. Moreover, the resulting view is dialectically unstable, since it threatens to undercut the motivation from accessibilism. In the next section, I'll argue that these problems for phenomenal conservatism are further compounded by its account of the evidential support relation.

\section{Problems about Evidential Support}

Let's turn now from evidence to evidential support. This section argues that the global ambitions of phenomenal conservatism depend on an overly simplified account of the evidential support relation. The global principle says that your evidence supports a proposition to the extent that it seems true: the more strongly it seems true, the more strongly it is supported by your evidence. This view distorts the epistemology of introspection, logic, and inference by subsuming them under the same model as perception. Perception is a bad model to extend because there are structural dimensions of epistemic rationality in these domains that have no analogue in perception.

In an evidentialist framework, epistemic rationality is a matter of proportioning your beliefs to the evidence: an epistemically rational thinker believes whatever their evidence supports. ${ }^{20}$ Phenomenal conservatism says that your evidence supports whatever seems true. Hence, an evidentialist version of phenomenal conservatism implies that an epistemically rational thinker believes whatever seems true. The problem is that all sorts of nonsense can seem true, including logical contradictions, Moorean conjunctions, and manifest falsehoods about your own experience. Phenomenal conservatism implies that epistemically rational thinkers can believe all this nonsense. Intuitively, however, this is beyond the pale as far as epistemic rationality is concerned. Therefore, phenomenal conservatism results in a distorted conception of epistemic rationality.

We cannot defend phenomenal conservatism against this objection by invoking constraints on what can seem true to epistemically rational thinkers. Epistemic rationality imposes no constraints on what can seem true, since the requirements of epistemic rationality don't apply to seemings. As Huemer (2001: 97) notes, it makes no sense to say that seemings are rational or irrational: this is a category mistake. There may be contingent constraints on what can seem true to human beings, but there are no necessary constraints on what can seem true to any possible thinker at all. To assume otherwise is to assume that there are brute necessary connections between seemings that cannot be further explained. It is much more plausible to assume a modal principle of recombination on which any seeming can be combined with any other seeming. If there are psychological constraints that apply to all possible thinkers as such, then these must be derived from the nature of epistemic

\footnotetext{
${ }^{20}$ Following Huemer (2001: 22), I use 'epistemic justification' and 'epistemic rationality' interchangeably: these are different terms that pick out the same property. Rejecting evidentialism by introducing non-evidential constraints on epistemic rationality would severely compromise the theoretical simplicity and unity of phenomenal conservatism.
} 
rationality. Since there are no rational constraints on seemings, however, there are no psychological constraints on seemings that apply to all possible thinkers.

This, in a nutshell, is my argument against phenomenal conservatism. In this section, I want to develop this argument by applying it to three kinds of examples: (i) introspective incoherence, (ii) logical incoherence, and (iii) meta-incoherence. I'll argue that phenomenal conservatism cannot explain why these extreme forms of incoherence are incompatible with epistemic rationality. To explain these limits on epistemic rationality, we need to impose structural constraints on the evidential support relation.

\subsection{Introspection}

Phenomenal conservatism says that introspective justification has its source in introspective seemings. On this view, I have introspective justification to believe that it perceptually seems to me that $p$ just when and because it introspectively seems to me that it perceptually seems to me that $p$. As a general rule, my seemings can be deceptive: things are not always how they seem. Assuming that introspective seemings are no exception to the rule, my first-order seemings and my higher-order seemings can diverge. Suppose it visually seems to me that $p$, but it introspectively seems that it doesn't visually seem that $p$. Phenomenal conservatism implies that, in the absence of defeaters, I have introspective justification to believe a false proposition about how things visually seem. Indeed, Huemer (2007: 35) explicitly says that false introspective beliefs about your experience can be justified on the basis of false introspective seemings. Are there any limits on how far this can go?

Could there be a case of rational "self-blindness" in which my beliefs about how things seem are fully rational but systematically false? Could I rationally believe, for example, that it seems as if I'm playing basketball with the Los Angeles Lakers, when in fact it seems as if I'm sitting here in my office writing philosophy? Sydney Shoemaker (1996) argues famously against the possibility of rational self-blindness, but his conclusion is much more plausible than his premises. Intuitively, it is just completely irrational to have beliefs about your experience that diverge so wildly from what your experience is really like. And yet phenomenal conservatism cannot explain this.

One potential response is to bite the bullet. It's a familiar Cartesian thought that I can be fully rational when I'm deceived by an evil demon into forming systematically false beliefs about the external world. But then why not say that I can be fully rational when I'm deceived by an evil demon into forming systematically false beliefs about my own experience? This response conflicts with the Cartesian idea that my beliefs about how things seem are epistemically more secure, and less vulnerable to skeptical doubts, than my beliefs about the external world. But what are the implications of rejecting Cartesian orthodoxy?

If I can rationally hold false beliefs about how things seem, then I'll need to revise my beliefs about the external world to cohere with my false beliefs about how things seem. Otherwise, I'm in danger of falling into an incoherent predicament in which I hold beliefs about the world that I believe to be unjustified by how things seem. In the absence of evidence that my seemings are unreliable, it is irrational for me to hold beliefs about the external world that conflict with my beliefs about how things seem. To avoid this kind of incoherence, my experience must be systematically disconnected from my perceptual beliefs 
about the external world as well as my introspective beliefs about my own experience. And yet this is surely beyond the pale as far as epistemic rationality is concerned.

Let's apply this reasoning to our example. Suppose I can rationally believe that it seems that I'm playing basketball, when it really seems that I'm sitting in my office. What should I believe about where I really am? There is no good answer to this question. One answer is that I should believe I'm teaching philosophy, since that's how things seem. Of course, I shouldn't believe that I should believe this, since I shouldn't believe that's how things seem. And yet rationality surely precludes believing something I believe I shouldn't believe. So this answer is no good. Another answer is that I should believe I'm playing basketball, since that's how I should believe things seem. And yet surely rationality requires that my beliefs cohere with how things seem and not just with my beliefs about how things seem. So this answer is no good either. And the same point rules out the answer that I should withhold belief about where I am. Either way, phenomenal conservatism generates unacceptable consequences.

The case I am considering is adapted from the "Strange Case of Magic Feldman" that was originally proposed by Richard Feldman:

Professor Feldman is a rather short philosophy professor with a keen interest in basketball. Magic Johnson (MJ) was an outstanding professional basketball player. While playing a game, we may suppose, MJ had a fully coherent system of beliefs. Magic Feldman (MF) is a possible, though unusual, character, who is a combination of the professor and the basketball player. MF has a remarkable imagination, so remarkable that while actually teaching a philosophy class, he thinks he is playing basketball. Indeed, he has exactly the beliefs MJ has. Because MJ's belief system was coherent, MF's belief system is also coherent. (2003: 68)

He proposes the case as a counterexample to pure coherentism, the thesis that your beliefs are epistemically justified when and only when they cohere with each other. It is a counterexample because Magic Feldman's beliefs are irrational, and so unjustified, despite the fact that they cohere with each other. Intuitively, epistemic rationality requires that your beliefs cohere with your experiences and not just with your other beliefs. Here is what I'm adding to the case: if your introspective beliefs fail to cohere with your experiences, then your perceptual beliefs must fail to cohere with your experiences too. Otherwise, you risk lapsing into meta-incoherence. Therefore, rationality requires that your introspective beliefs must cohere with your experiences. Otherwise, we're forced to accept the counterintuitive result that Magic Feldman can be fully rational.

What we've just seen is an argument that fully rational self-blindness is impossible. If your introspective beliefs are systematically mistaken, then either your perceptual beliefs fail to cohere with your introspective beliefs or they fail to cohere with your perceptual experiences. Either way, you systematically violate the requirements of epistemic rationality. The problem for phenomenal conservatism is that it fails to explain why this kind of rational self-blindness is impossible. If it's sometimes rationally permissible to form false beliefs about how things seem, then why not always? Phenomenal conservatism imposes no principled limits on how far our first-order seemings can diverge from our higher-order seemings. Given that epistemic rationality requires conforming your introspective beliefs to 
your introspective seemings, it follows that there are no principled limits on how much introspective error is consistent with epistemic rationality.

Perhaps only an alien psychology could produce such a massive divergence between first-order seemings and higher-order seemings. Even so, it is hard to rule out this possibility in principle. After all, delusions like Anton's syndrome provide real life examples of systematic introspective error in which people who are blind believe they can see. The problem is that phenomenal conservatism cannot explain why such an alien psychology would be irrational. After all, there is nothing irrational about an alien psychology per se.

Another response is to block this objection by endorsing a self-presentational theory of experience, according to which all experiences are "self-presenting" in the sense that they represent themselves with presentational force. On this view, it's a necessary truth that if it seems $_{1}$ that $p$, then it thereby seems ${ }_{2}$ that it seems ${ }_{1}$ that $p$. As far as I can see, there are no good reasons to accept this theory aside from its role in rescuing phenomenal conservatism from counterexamples. On the other hand, there are good reasons to reject this theory, since it generates an infinite regress: if it seems $s_{1}$ that $p$, then it seems $s_{2}$ that it seems $s_{1}$ that $p$, and it seems $_{3}$ that it seems $s_{2}$ that it seems ${ }_{1}$ that $p$, and so on ad infinitum. Moreover, this infinite regress is vicious, rather than virtuous. It can seem to me that I have hands without thereby seeming to me that any infinitely long and complicated higher-order proposition about my seemings is true. Moreover, these are not just different descriptions of one and the same seeming. After all, my seeming that I have hands has a simpler content and a different subject matter: it is about how things are, rather than how they seem. ${ }^{21}$

A better explanation of the impossibility of rational self-blindness appeals to the simple theory of introspection (see section 3). The simple theory says that the phenomenal facts about how things seem are selfevident in the sense that they constitute conclusive evidence for themselves:

Self-Evidence of Seemings: Necessarily, if it seems to you that $p$, then it's evidentially certain that it seems to you that $p$.

To explain the impossibility of rational self-blindness, we needn't rule out the possibility of alien psychologies in which beliefs about how things seem are systematically divorced from the facts about how things seem. Instead, we should say that this kind of systematic error is epistemically irrational, even if it's psychologically possible, because epistemic rationality requires introspective self-knowledge. Epistemically rational thinkers always know the phenomenal facts about how things seem because these phenomenal facts are self-evident. Epistemically rational thinkers always proportion their beliefs to the evidence: they believe whatever the evidence supports.

\subsection{Logic and Inference}

Phenomenal conservatism says that a priori justification for beliefs about logic has its source in intellectual seemings. On this view, I have a priori justification to believe that $p$ just

${ }^{21}$ See Stoljar (2018) for a more detailed presentation of the regress argument. 
when and because it intellectually seems to me that $p$ in the absence of defeaters. And yet my intellectual seemings, just like my perceptual seemings, can be deceptive. Suppose it seems to me that affirming the consequent is valid, that modus ponens is invalid, and so on. Phenomenal conservatism implies that, in the absence of defeaters, I have justification to believe all these logical falsehoods. Are there any limits on how far this can go?

Let's revisit the Cartesian thought that I can be fully rational even when I'm deceived by an evil demon into forming systematically false beliefs about the external world. Can we extend this Cartesian thought from contingent truths about my perceptible environment to necessary truths about logic? Intuitively, not: my rationality is compromised by systematic error about logic but not by systematic error about my perceptible environment. Suppose an evil demon ensures that the most basic logical truths seem false and the most basic logical falsehoods seem true. Intuitively, this undermines my rationality, rather than leaving my rationality intact.

As before, one response is to bite the bullet. On this view, epistemic rationality is compatible with systematic error about logic. But we can put pressure on this response by considering the connections between logical belief and logical inference. If you believe that affirming the consequent is a valid form of argument, and you believe that some inference instantiates that form, then you're rationally committed to making the inference: that is, either believing the conclusion or withholding belief in at least one of the premises. Otherwise, you're susceptible to incoherence: you believe the premises of an argument, and you believe the conclusion follows, but you're unwilling to infer the conclusion from the premises. Similarly, if you believe that modus ponens is an invalid form of argument, and you believe that some inference instantiates that form, and no valid form, then you're rationally committed to refrain from making the inference. Otherwise, you're incoherent: you believe the premises of an argument, and you're willing to infer the conclusion from those premises, although you don't believe the conclusion follows from those premises.

To avoid this kind of incoherence, you must be willing to put your logical beliefs into practice by making the corresponding logical inferences. If you believe that affirming the consequent is a valid form of argument, then you must be disposed to make inferences that affirm the consequent. And if you believe that modus ponens is an invalid form of argument, then you must be disposed to refrain from making inferences by modus ponens. And yet these inferential dispositions are beyond the pale as far as epistemic rationality is concerned. Anyone who is systematically disposed to affirm the consequent, but not to infer by modus ponens, is grossly irrational. Epistemically rational thinkers are logical thinkers: they reason in ways that respect logic. Therefore, epistemically rational thinkers, when they are reflective, must form true beliefs about logic. We all make mistakes, of course, but someone whose logical beliefs and logical reasoning systematically fail to respect logic is not an epistemically rational thinker at all.

What we've just seen is an argument that rational blindness about logic is impossible. If your beliefs about logic are systematically mistaken, then either your reasoning fails to cohere with your beliefs about logic or your reasoning fails to respect logic. Either way, you systematically violate the requirements of epistemic rationality. The problem for phenomenal conservatism is that it fails to explain why epistemic rationality prohibits this kind of systematic error about logic. If it's sometimes rationally permissible to form false beliefs 
about logic, then why not always? Phenomenal conservatism imposes no principled limits on the extent to which our intellectual seemings can be mistaken. Given that epistemic rationality requires conforming our beliefs about logic to our logical seemings, there can be no principled limits on how much logical error is consistent with epistemic rationality.

Similar problems arise for Huemer's (2016) account of inferential justification. On this view, inferential justification has its source in inferential seemings: you have epistemic justification to deduce a conclusion from some premises just when and because the following conditions hold in the absence of defeaters: (i) the premises seem true, (ii) the conclusion seems to follow from the premises, and (iii) the conclusion thereby seems true. As Huemer puts the point, my inferential seeming "represents that a certain conclusion must be correct, in the light of a certain premise that I already accept" (2016: 149).

This account implies that I have epistemic justification to make fallacious inferences whenever the conclusions of such inferences seem true because they seem to follow from premises that seem true. Huemer (2016: 147) defends this claim by giving the case of a skilled but unfortunate mathematician, who makes a subtle fallacy in attempting to prove a theorem. The problem is that Huemer must count as rational not only these subtle and occasional errors in reasoning, but also elementary and chronic errors in reasoning. After all, there is nothing to rule out the possibility that someone might systematically represent all fallacious arguments as valid and all valid arguments as fallacious.

Another problematic consequence is that Huemer is committed to rejecting the following principle of single-premise closure:

Closure: Necessarily, if $p$ entails $q$, and you have justification to believe that $p$, then you have justification to believe that $q$.

Even if the premises of a valid argument seem true, the conclusion may fail to seem true in light of the premises because the argument doesn't seem valid. In light of this point, some proponents of phenomenal conservatism may be tempted to abandon this closure principle and replace it with the following revised version:

Revised Closure: Necessarily, if you have justification to believe that $p$ entails $q$, and you have justification to believe that $p$, then you have justification to believe that $q$.

But Huemer must reject the revised version too. After all, it might seem to you that a conclusion follows from some premises, and it might seem to you that the premises are true, without thereby seeming to you that the conclusion is true. This is what happens to many of us when we consider Vann McGee's (1985) counterexamples to modus ponens. The problem is that phenomenal conservatism imposes no principled limits on how often this can happen. As a result, it allows for epistemically rational thinkers who never infer conclusions that seem to follow from premises that seem true, since those conclusions never seem true. Intuitively, however, such thinkers are grossly irrational.

Can we block these objections by appealing to facts about defeaters? It is not clear that we can, since phenomenal conservatism says that my intellectual seemings can be defeated only by conflicting seemings. Suppose it intellectually seems to me clearly and 
unequivocally that affirming the consequent is valid, that modus ponens is invalid, and so on. In that case, phenomenal conservatism implies that I have undefeated justification to believe these logical falsehoods, since I have no conflicting seemings.

Can we block the objection by appealing instead to the conditions for possessing logical concepts? The idea is that possessing logical concepts requires some capacity to use them correctly in logical reasoning. ${ }^{22}$ On this view, it's incoherent to suppose that someone possesses logical concepts without having any capacity to use them correctly. One problem is that the conditions for possessing logical concepts must be minimal enough to allow for the kinds of logical mistakes that we routinely find in normal and delusional humans. Presumably, you can satisfy these minimal conditions for possessing logical concepts while making enough mistakes about logic to fall below the threshold for epistemic rationality. That is all we need for our argument against phenomenal conservatism to succeed.

A more fundamental problem is that phenomenal conservatism cannot explain why possessing logical concepts should require the ability to use them correctly. This cannot be a general requirement on concept possession. Otherwise, we're forced to deny that the victim of the evil demon can form beliefs about the external world that are systematically false. Why should this requirement apply to logical concepts but not empirical concepts? One good answer appeals to rationality constraints on concept possession together with a more specific connection between epistemic rationality and logical truth. The problem is that phenomenal conservatism makes no such connection between epistemic rationality and logical truth. As a result, it cannot rule out the possibility of subjects that use logical concepts in a way that is epistemically rational but nevertheless systematically mistaken.

To explain why systematic logical blindness is epistemically irrational, we need some connection between epistemic rationality and logical truth. Many formal theories of epistemic rationality build such a connection into their account of the evidential support relation. On a probabilistic conception of the evidential support relation, for example, all logical truths are evidentially certain: that is, they always have evidential probability 1 . The nature of the evidential support relation guarantees that any possible body of evidence provides conclusive support for any logical truth. On this view, all logical truths are self-evident in the following sense:

Self-Evidence of Logical Truths: Necessarily, if it's a logical truth that $p$, then it's evidentially certain that $p$.

If all logical truths are self-evident in this sense, then we can explain why systematic logical blindness is epistemically irrational. This is an egregious violation of the rational requirement that you should proportion your beliefs to the evidence. Epistemically rational thinkers are logically omniscient because they believe whatever their evidence supports and their evidence conclusively supports every logical truth.

\footnotetext{
${ }^{22}$ See Peacocke (1992: Ch. 1) for an account of the possession conditions for logical concepts that requires a disposition to use valid forms of argument.
} 


\subsection{Meta-Coherence}

The two problems just considered generate a third problem, which Huemer (2011) calls "the puzzle of meta-coherence". Suppose it seems to me that $p$, although it doesn't seem that I have justification to believe that $p$; in fact, it seems that I don't have justification to believe that $p$. This can happen in at least two different ways. First, introspective seemings can be deceptive: it can seem that $p$, although it introspectively seems that it doesn't seem that $p$. Second, intellectual seemings can be deceptive: even if phenomenal conservatism is true, it can intellectually seem to me that it's false, and hence that I don't have justification to believe that things are the way they seem. Either way, it can seem to me that $p$, while it also seems that I don't have justification to believe that $p .{ }^{23}$

Here is the problem. Phenomenal conservatism implies that, in the absence of defeaters, I have epistemic justification to be in an incoherent kind of akratic predicament: that is, to believe that $p$, while also believing that I lack justification to believe that $p$. If so, then I have epistemic justification to believe a Moorean conjunction of the following form:

$p$ and I don't have justification to believe that $p$.

But this is absurd! Intuitively, I cannot have epistemic justification to believe a Moorean conjunction of this form. Moreover, this intuition can be supported by argument: (i) the Moorean conjunction is knowably unknowable, but (ii) I cannot have epistemic justification to believe that $p$ when it is knowably unknowable that $p$, so (iii) I cannot have epistemic justification to believe this Moorean conjunction. ${ }^{24}$

As always, one reaction is to bite the bullet by maintaining that epistemic akrasia is sometimes rational after all. It's noteworthy, however, that Huemer doesn't adopt this response here. Instead, he endorses the following requirement of epistemic rationality:

The Metacoberence Requirement. Categorically believing that $p$ commits one, on reflection, to the view that one knows that $p$. (2011: 2)

The idea is that if you believe that $p$, while also believing that you're not in a position to know that $p$, then you're thereby irrational; or, anyway, less than fully rational. On this view, epistemic rationality requires meta-coherence.

The problem is that phenomenal conservatism cannot explain why meta-incoherence is always epistemically irrational. This is because it imposes no principled limits on how far our first-order seemings can diverge from our higher-order seemings about justification. As we've seen, it cannot rule out the possibility that it seems to me that $p$, although it seems that I don't have justification to believe that $p$. On this view, epistemic rationality is just a matter of believing what seems strongly enough on balance to be true. But nothing rules out the

${ }^{23}$ Hasan (2013: 135-136) considers similar examples in exploring the difficulties of reconciling phenomenal conservatism with accessibilism.

${ }^{24}$ For further discussion of the irrationality of epistemic akrasia and the related phenomenon of believing Moorean conjunctions, see Smithies (2019: Chs. 9 \& 10). 
possibility that Moorean conjunctions might seem on balance to be true. Therefore, phenomenal conservatism cannot explain why epistemic rationality prohibits believing these Moorean conjunctions.

Huemer (2011) proposes to solve the problem of meta-coherence by appeal to defeaters. He argues that your justification to believe that $p$ is defeated by anything that justifies disbelieving or withholding belief in the metajustificatory proposition that you have justification to believe that $p$. This includes both cases in which it seems that the metajustificatory proposition is false and cases in which it doesn't seem that the metajustificatory proposition is true. Either way, your justification to believe that $p$ is defeated. This is how Huemer seeks to explain why you cannot have epistemic justification to believe Moorean conjunctions of the following form: $p$ and I don't have justification to believe that $p$.

My objection is that Huemer's solution assumes that epistemic rationality requires meta-coherence without explaining why it does. His key claim is that anything that justifies disbelieving or withholding belief that you have justification to believe that $p$ thereby defeats your justification to believe that $p$. Contraposing, you have justification to believe that $p$ only if you lack justification to disbelieve or withhold belief in the metajustificatory proposition. But if you lack justification to disbelieve or withhold belief in the metajustificatory proposition, then you have justification to believe it instead. This is a consequence of the existence thesis, which says that you always have justification to adopt some doxastic attitude towards any given proposition. Thus, Huemer's solution assumes the left-to-right direction of the JJ principle below:

The JJ Principle: Necessarily, you have justification to believe that $p$ if and only if you have justification to believe that you have justification to believe that $p$.

Perhaps Huemer will reject the existence thesis unless it is restricted to propositions that you've entertained. Even so, he is still committed to a restricted version of the JJ principle that applies whenever you consider whether the metajustificatory proposition is true.

This structural principle about epistemic justification needs to be explained, but phenomenal conservatism doesn't provide the resources to explain it. Phenomenal conservatism says that you have justification to believe whatever seems strongly enough on balance to be true. But Moorean conjunctions can seem strongly and on balance to be true. So phenomenal conservatism doesn't explain why you cannot have epistemic justification to believe Moorean conjunctions even when they seem true. The upshot is that phenomenal conservatism cannot explain why epistemic rationality requires meta-coherence without abandoning its global ambitions to subsume all the requirements of epistemic rationality under a single epistemic principle. ${ }^{25}$

${ }^{25}$ More generally, claims about defeat often smuggle in substantive assumptions about the structure of the evidential support relation that are hard to reconcile with the global ambitions of phenomenal conservatism. For example, it's hard to explain why the justification provided by seemings is subject to rebutting and undercutting defeat without appealing to logical and probabilistic constraints on the evidential support relation. 
In order to explain why epistemic rationality requires meta-coherence, we need to build more structure into our account of the evidential support relation. More specifically, we need the probabilistic version of accessibilism below:

Accessibilism: Necessarily, if the evidential probability that $p$ is $n$, then it's evidentially certain that the evidential probability that $p$ is $n$.

This principle explains why epistemic rationality requires meta-coherence. Violations of meta-coherence are violations of the rational requirement that you should proportion your beliefs to the evidence. Epistemically rational thinkers are always meta-coherent because they proportion their beliefs to the evidence and no possible body evidence supports a metaincoherent combination of beliefs.

\subsection{The Overkill Objection}

My solution to these problems might seem like overkill. I started with the intuition that epistemic rationality is incompatible with systematic violations of introspective coherence, logical coherence, and meta-coherence. I argued that phenomenal conservatism cannot explain these intuitions about the nature of epistemic rationality. Instead, we need to build more structure into the evidential support relation. But this solution implies something much stronger than what we started with: namely, that epistemic rationality is incompatible with even the smallest violation of introspective coherence, logical coherence, and metacoherence. Many philosophers have the reaction that this is simply much too demanding.

My response is that epistemic rationality is an evaluative ideal of good reasoning. Given our contingent human limitations, we are not capable of perfectly realizing this ideal, but we can approximate towards the ideal to a greater or lesser extent. What our ordinary evaluations of epistemic rationality are tracking, in some rough and ready way, are various dimensions of approximation towards the ideal. We count extreme violations of coherence requirements as epistemically irrational because they depart so egregiously from the ideal. We tend to count ourselves as epistemically rational because our own violations are much less egregious: we approximate closely enough to the ideal to meet some contextually determined threshold that takes our human limitations into account. But someone who perfectly realizes the ideal of epistemic rationality never violates these coherence requirements.

I'm not saying that the ideal of epistemic rationality is one that we humans can realize when we're in optimal conditions for the operation of our psychological machinery. We may be constitutionally incapable of realizing the ideal. It seems possible in principle that there could be a perfectly rational agent - perhaps a god or an angel - although its capacities would need to be superhuman and perhaps even infinite. But suppose the possibility of a perfectly rational agent is ruled out by the small print in the laws of metaphysics. It is not at all clear why this should matter. What matters is that we can make sense of degrees of epistemic rationality - whether or not we can model them precisely in a formal framework and that there is some recognizable epistemic value in having greater, rather than lesser, degrees of epistemic rationality. 
Any plausible theory of epistemic rationality needs to account for intuitions about what agents "should" believe and do when they are incapable of complying with its own requirements. Even phenomenal conservatism needs some version of this distinction. After all, we are not always capable of complying with the requirement to conform our beliefs to the way things seem. Sometimes, we cannot form epistemically justified beliefs on the basis of our perceptual evidence, since our belief-forming dispositions are insufficiently sensitive to unattended or fine-grained aspects of our perceptual experience. ${ }^{26}$ It makes sense to ask what we "should" believe in light of these psychological limitations: some policies are more reasonable than others as ways of coping with our limitations. This is just another instance of the distinction between ideal and non-ideal standards of epistemic rationality. I don't see how any plausible theory of epistemic rationality can do without it. ${ }^{27}$

\section{Phenomenal Accessibilism}

The previous section raised a series of objections to phenomenal conservatism that all have the same basic structure. The starting point is some platitude about the nature of epistemic rationality. For example, all epistemically rational thinkers have the following characteristics:

(1) Perceptual Coherence: Necessarily, epistemically rational thinkers hold perceptual beliefs about the external world that cohere with how things perceptually seem.

(2) Introspective Coherence: Necessarily, epistemically rational thinkers hold introspective beliefs about how things seem that cohere with how things seem.

(3) Logical Coherence: Necessarily, epistemically rational thinkers hold beliefs that cohere logically or probabilistically with their other beliefs.

(4) Meta-Coherence: Necessarily, epistemically rational thinkers hold beliefs that cohere with their higher-order beliefs about which beliefs they should hold.

The objection is that phenomenal conservatism cannot explain all these characteristics of epistemically rational thinkers. According to phenomenal conservatism, epistemic rationality is a matter of believing whatever seems strongly enough on balance to be true. The problem is that things are not always how they seem: if we have introspective, intellectual, and inferential seemings, then these seemings can be systematically deceptive. Therefore, phenomenal conservatism implies that epistemically rational thinkers can be deeply incoherent among all but one of the dimensions listed above. Since this is implausible, we should reject phenomenal conservatism.

Phenomenal conservatism implies that the beliefs of epistemically rational thinkers cohere with their perceptual appearances, although their beliefs need not be introspectively coherent, logically coherent, or meta-coherent. In effect, its account of the nature of

\footnotetext{
${ }^{26}$ See Smithies (2019: Ch. 3) for more on conscious perception without attention and Smithies (2019: Ch. 11) on the problem of the speckled hen.

${ }^{27}$ See Smithies (2019: Ch. 10) on ideal versus non-ideal requirements of rationality.
} 
epistemic rationality preserves some dimensions of coherence at the expense of others. Quite plausibly, however, the beliefs of epistemically rational agents are coherent in all of these ways. There is no principled motivation for privileging just one of these dimensions of coherence over the others. On the contrary, this is merely an artifact of the global ambition to explain all epistemic justification in terms of the perceptual model.

This suggests a diagnosis of why phenomenal conservatism results in such a distorted account of the nature of epistemic rationality. Generalizing the perceptual model of evidential support results in an overly simplistic account of the evidential support relation. Perceptual experience provides defeasible evidential support for its contents by making them seem true: this is why you have justification to believe the contents of perceptual experience. In effect, phenomenal conservatism assumes that this is the only constraint on the evidential support relation. This is the source of the global principle that your evidence supports a proposition just when it seems strongly enough on balance to be true. The problem is that perception is a bad model to generalize to other domains because there are dimensions of epistemic rationality that it fails to explain. Epistemic rationality requires not just perceptual coherence, but also introspective coherence, logical coherence, and meta-coherence.

To avoid these problems for phenomenal conservatism, we need an account of the evidential support relation that builds in enough structure to explain all the essential features of epistemically rational thinkers. It is a necessary truth about the nature of epistemic rationality that epistemically rational thinkers are coherent in all these ways. We cannot explain these necessary truths about the nature of epistemic rationality in terms of contingent facts about what seems true to epistemically rational thinkers. After all, epistemic rationality doesn't impose any constraints on how things seem. Instead, we need to explain the nature of epistemic rationality in terms of necessary truths about the evidential support relation that hold for all thinkers regardless of the contingent facts about what evidence they happen to have. That is the overarching point that I want to insist upon.

Let's start with perceptual coherence: why do epistemically rational thinkers hold perceptual beliefs about the external world that cohere with how things perceptually seem? We can explain this in terms of a probabilistic constraint on the evidential support relation:

Explaining Perceptual Coherence: Necessarily, if it seems to you that $p$ in the absence of defeaters, then it is evidentially probable that $p$.

According to this principle, it's an a priori necessary truth about the evidential support relation that things are probably the way they seem in the absence of defeaters. This explains why epistemically rational thinkers form beliefs about the world that cohere with their perceptual appearances. Epistemically rational thinkers proportion their beliefs to their evidence: they believe what is sufficiently probable given their evidence. ${ }^{28}$

\footnotetext{
${ }^{28}$ There are probabilistic constraints on what counts as a defeater: if $d$ defeats the support that $e$ provides for $p$, then the evidential probability that $p$ given the conjunction of $e$ and $d$ is lower than the evidential probability that $p$ given $e$ alone.
} 
Here is a related question: why do epistemically rational thinkers tend to rely on the contents of their beliefs as premises in reasoning? Again, we can explain this in terms of a formal constraint on the evidential support relation:

Explaining Doxastic Coherence: Necessarily, if you believe that $p$ in the absence of defeaters, then it is evidentially probable that $p$.

According to this principle, it's an a priori necessary truth about the evidential support relation that things are probably the way you believe them to be in the absence of defeaters. This is why epistemically rational thinkers tend to use the contents of their beliefs as premises in reasoning. After all, epistemically rational thinkers proportion their beliefs to the evidence: they believe what is sufficiently probable given their evidence. Beliefs don't raise the probability of their contents as much as perceptual seemings. After all, when conflicts arise, epistemically rational thinkers tend to revise their beliefs in light of their perceptual seemings, rather than regarding their perceptual seemings as unreliable. Even so, this default can be overridden by strong enough evidence that your perceptual seemings are unreliable.

What about introspective coherence, logical coherence, and meta-coherence? In section 4, I argued that we can explain these essential features of epistemically rational thinkers by building the following structural constraints into the evidential support relation:

Self-Evidence of Seemings: Necessarily, if it seems to you that $p$, then it's evidentially certain that it seems to you that $p$.

Self-Evidence of Logical Truths: Necessarily, if it's a logical truth that $p$, then it's evidentially certain that $p$.

Accessibilism: Necessarily, if the evidential probability that $p$ is $n$, then it's evidentially certain that the evidential probability that $p$ is $n$.

These structural constraints on the evidential support relation explain why epistemically rational agents are not only perceptually coherent, but also introspectively coherent, logically coherent, and meta-coherent. Epistemically rational agents are always coherent in these ways because they always proportion their beliefs to the evidence and their evidence always supports a coherent set of beliefs.

Now we face a unification challenge. Is there anything that unifies this laundry list of constraints on the evidential support relation? If not, then the lingering suspicion will remain that we should prefer phenomenal conservatism on grounds of theoretical unity and simplicity. My answer to the challenge is that the principles in this list can be unified within the framework of accessibilism. I'll make three points in this connection.

The first point is that we can derive the conclusion that all seemings are self-evident from the premise that all seemings are evidence together with the further premise that all evidence is self-evident:

Self-Evidence of Evidence: Necessarily, if your evidence includes the fact that $p$, then it's evidentially certain that $p$. 
In section 3, I argued that all seemings are evidence, though not all evidence is seemings. But why suppose that all evidence is self-evident? The evidential probability that $p$ is equal to the probability that $p$ conditional upon your evidence: if your evidence includes the fact that $p$, then your evidence entails that $p$, and hence the evidential probability that $p$ is 1 . This means that epistemically rational thinkers always know what their evidence is, including the phenomenal facts about how things seem.

The second point is that the self-evidence of logical truths can be derived from the more general principle that all epistemically necessary truths are self-evident, including truths about the evidential support relation as well as truths about logic. On this view, evidential support facts are self-evident in just the same way as logical facts:

Self-Evidence of Evidential Support. Necessarily, if evidence $e$ makes it evidentially probable that $p$ to degree $n$, then it's evidentially certain that evidence $e$ makes it evidentially probable that $p$ to degree $n$.

Epistemically necessary truths are truths that are conclusively justified on a priori grounds. On David Chalmers' (2011) epistemic interpretation of the probability calculus, they are true everywhere in the probability space, and so they have evidential probability 1. I've given no general formula for deciding which truths are epistemically necessary in this sense, but there are good reasons to include truths about logic and evidential support.

The third point is that accessibilism is true just because facts about your evidence, and facts about the evidential support relation, are self-evident in the sense just defined. Necessarily, if your evidence $e$ makes it evidentially probable that $p$ to degree $n$, then it is evidentially certain that (i) you have evidence $e$, and (ii) if you have evidence $e$, then it is evidentially probable that $p$ to degree $n$, so (iii) it is evidentially probable that $p$ to degree $n$. Hence, accessibilism is not an extra constraint on the evidential support relation: it stands or falls with the other constraints just mentioned, rather than dangling loosely on its own.

What motivates all these constraints on the evidential support relation is that epistemic rationality requires meta-coherence. It is hard to explain this unless we suppose that facts about your evidence, and facts about what it supports, are self-evident. If you can have misleading higher-order evidence about what your evidence supports, then it is sometimes rationally permissible to be meta-incoherent. Since it is never rationally permissible to be meta-incoherent, it follows that you can never have misleading higherorder evidence about what your evidence supports. This is precisely because facts about your evidence, and facts about the evidential support relation, are self-evident in the sense we've defined. On this view, epistemically rational agents are not only logically omniscient, but also evidentially omniscient in the sense that they are always certain of what their evidence is and what it supports. This explains why epistemically rational agents are always meta-coherent. ${ }^{29}$

This answer to the unification challenge illuminates the unity of the epistemic virtues. Epistemic rationality requires being coherent along multiple dimensions: perceptual

${ }^{29}$ This argument is developed at length in Smithies (2019: Ch. 10). 
coherence, introspective coherence, logical coherence, and meta-coherence. What do all these dimensions of coherence have in common? We can now see what unifies these virtues of epistemic rationality. Epistemically rational thinkers are coherent because they believe what their evidence supports and their evidence is guaranteed to support coherent beliefs. These coherence constraints are built into the nature of the evidential support relation in a principled and unified way. The resulting theory is admittedly more complex than phenomenal conservatism, but it is also much simpler and more unified than it might initially seem. Moreover, the additional complexity of the theory is justified by its explanatory power, since we need this extra structure in our account of the evidential support relation in order to explain the nature of epistemic rationality.

In summary, phenomenal conservatism cannot explain why epistemic rationality requires coherence. This is because it operates with an overly simplified account of the evidential support relation, according to which your evidence supports a proposition to the extent that it seems true. In order to explain why epistemic rationality requires coherence, we need to build more formal structure into our account of the evidential support relation. In particular, we need to endorse accessibilism: the thesis that facts about your evidence, and facts about the evidential support relation, are self-evident.

Why can't proponents of phenomenal conservatism simply abandon the project of explaining the evidential support relation and settle for an account of evidence instead? There is nothing wrong with combining a phenomenal conception of evidence with accessibilism about the evidential support relation: indeed, that is exactly my view. But this is to abandon all but the weakest of our three principles of phenomenal conservatism. Here's why. Even if your evidence is exhausted by how things seem, your evidence can support $p$, and thereby give you epistemic justification to believe that $p$, even when it doesn't seem that $p$. This is because the nature of the evidential support relation guarantees that you have epistemic justification to believe certain propositions even when they don't seem true.

Logical truths provide the simplest illustration of this point. On a probabilistic conception of evidential support, every logical truth is entailed by your evidence, and thereby conclusively supported by your evidence, whether or not it seems true. This generates counterexamples to the strong principle of phenomenal conservatism, since you have epistemic justification to believe logical truths even when they don't seem true. The same point holds more generally in the following examples:

(1) If it seems that $p$, then you have justification to believe that it seems that $p$, even when it doesn't seem that it seems that $p$. More generally, if you have evidence $e$, then you have justification to believe that you have evidence $e$, even when it doesn't seem that you have evidence $e$.

(2) If your evidence $e$ supports $p$, then you have justification to believe that evidence $e$ supports $p$, even when it doesn't seem that $e$ supports $p$. More generally, you have justification to believe any epistemically necessary truth that $p$, even when it doesn't seem to you that $p$.

(3) If you have justification to believe that $p$, then you have justification to believe that you have justification to believe that $p$, even when it doesn't seem to you that you have justification to believe that $p$. 
(4) If you have justification to believe that $p$, and $p$ entails $q$, then you thereby have justification to believe that $q$, even if it doesn't seem to you that $q$ is true in light of $p$.

The general point is that, even if your evidence is exhausted by seemings, it can support a proposition that doesn't seem true. This is because some propositions are supported by your evidence in virtue of structural facts about the evidential support relation that hold necessarily whatever evidence you contingently happen to have. Epistemic justification is not grounded solely in how things seem, since it is grounded partially in facts about the nature of the evidential support relation. This is another reason why the global ambitions of phenomenal conservatism are doomed to fail. Its account of the evidential support relation, as well as its account of evidence, is much too simple.

A corollary of this argument against phenomenal conservatism is that we have no good reason to believe that we have introspective, intellectual, or inferential seemings. This is not to deny that we have experiences associated with introspection, intuition, or inference, which assertively represent their contents to be true. The claim is, rather, that these experiences do not have the right kind of phenomenal character to play the same epistemic role as perceptual experience. The argument for this claim depends on epistemological considerations, rather than introspection or semantics. As we've seen, the global ambitions of phenomenal conservatism are doomed to fail because these experiences cannot play the same kind of epistemic role as perception.

To contrast my own view with phenomenal conservatism, I propose to call it "phenomenal accessibilism". The main point of agreement between these views is that we need a phenomenal conception of evidence. One point of disagreement concerns whether your evidence is restricted to phenomenal facts about how things seem. In section 3, I argued for a more liberal version of the phenomenal conception of evidence, which includes all the phenomenally individuated facts about your experiences and standing attitudes. Another point of disagreement concerns the evidential support relation. Phenomenal conservatism says that your evidence supports a proposition to the extent that it seems true. In contrast, phenomenal accessibilism says that your evidence supports a proposition to the extent that it is probable given your evidence, where evidential probability is constrained by a probabilistic version of accessibilism. This disagreement is more fundamental. Even if we assume that your evidence is constituted by facts about how things seem, a proposition can be probable given your evidence when it doesn't seem true. Phenomenal conservatism and phenomenal accessibilism deliver different verdicts in such cases.

The contrast between phenomenal conservatism and phenomenal accessibilism becomes crucial when we consider the motivations for endorsing the phenomenal conception of evidence in the first place. The best argument appeals to accessibilism: epistemic justification is luminous only if your evidence is luminous, but your evidence is luminous only if the phenomenal conception of evidence is true. I've argued that phenomenal conservatism conflicts with accessibilism both in its account of evidence and its account of the evidential support relation. Hence, phenomenal conservatism undermines its own best motivation. To defend the phenomenal conception of evidence in a principled way, we need to endorse phenomenal accessibilism instead. 


\section{Conclusions}

Here is a summary of the main conclusions of this paper.

Conclusion \#1: Weak phenomenal conservatism is true. This explains why perceptual experiences justify believing their contents. After all, perceptual experiences are seemings: they are experiences that forcefully represent their contents. Moreover, it is because they forcefully represent their contents that they can justify believing their contents without standing in need of justification themselves. Weak phenomenal conservatism, in combination with representationalism, implies that perceptual experience justifies belief about the external world in virtue of its phenomenal character alone. Hence, weak phenomenal conservatism provides an attractive framework for explaining the essential role of phenomenal consciousness in the epistemology of perception.

Conclusion \#2: Global phenomenal conservatism is false. We cannot explain all epistemic justification on the perceptual model, since this results in a distorted account of the nature of epistemic rationality. On this view, your evidence supports a proposition whenever it seems true. Since epistemic rationality requires believing whatever your evidence supports, it follows that epistemically rational thinkers believe whatever seems true. This fails to explain why epistemically rational thinkers are not only perceptually coherent, but also introspectively coherent, logically coherent, and meta-coherent. To explain these essential features of epistemically rational thinkers, we need to build more structure into our account of the evidential support relation.

Conclusion \#3: Strong phenomenal conservatism is false. Building more structure into our account of the evidential support relation generates counterexamples in which you have epistemic justification to believe propositions that don't seem true. This is because your evidence can support propositions in virtue of structural features of the evidential support relation, which hold necessarily whatever evidence you contingently happen to have. On this version of evidentialism, epistemic justification is not grounded wholly in contingent facts about your evidence, but partially in necessary facts about the evidential support relation.

Conclusion \#4: There are no seemings besides perceptual seemings: only perceptual experience and perceptual memory represent their contents with presentational force. We have intellectual experiences of intuition, inference, and introspection, but these experiences do not have the right kind of phenomenal character to play the same epistemic role as perceptual experience. This conclusion is not based on introspection, or ordinary language, but on epistemological considerations. The arguments against strong and global phenomenal conservatism show that cognitive experience cannot play the same epistemic role as perceptual experience.

Conclusion \#5: To explain the essential features of epistemically rational thinkers, we need to abandon phenomenal conservatism in favor of phenomenal accessibilism. On this view, there are structural constraints built into the evidential support relation, which guarantee that your evidence always supports a coherent set of beliefs. More precisely, facts about your evidence, and facts about the evidential support relation, are self-evident in the sense that they are made certain by your evidence. Epistemically rational thinkers are not 
only perceptually coherent, but also introspectively coherent, logically coherent, and metacoherent, because they always believe what their evidence supports.

Conclusion \#6: Phenomenal accessibilism fits better than phenomenal conservatism with the theoretical motivations for endorsing the phenomenal conception of evidence. The strongest argument for the phenomenal conception appeals to accessibilism: epistemic justification is luminous only if your evidence is luminous, but your evidence is luminous only if the phenomenal conception of evidence is true. Phenomenal conservatism cannot explain this structural constraint on the evidential support relation without abandoning its own global ambitions. Hence, phenomenal conservatism is self-defeating in the sense that it undercuts its own best motivation.

Conclusion \#7: There is no principled motivation for a version of the phenomenal conception that restricts your evidence to phenomenal facts about how things seem. This restriction is not motivated by accessibilism, which provides the best argument for the phenomenal conception in the first place. Moreover, this restriction results in an implausible account of the epistemology of introspection and memory. There is some pressure to avoid these problems by endorsing a diachronic version of the phenomenal conception of evidence, but this is inconsistent with accessibilism. Once again, the restricted version of the phenomenal conception of evidence undercuts its own best motivation.

Conclusion \#8: We should endorse a more liberal version of the phenomenal conception of evidence, which includes not only phenomenal facts about how things seem, but all phenomenal facts about your experience, and all phenomenally individuated facts about your standing propositional attitudes, including your beliefs, desires, and intentions. On this view, your evidence includes all and only the phenomenally individuated facts about your current mental states. This results in a more plausible account of the epistemology of introspection and memory. Moreover, it fits better with the motivations for endorsing the phenomenal conception of evidence in the first place. 


\section{References}

Bengson, John. 2015. “The Intellectual Given.” Mind 124: 707-760.

Brogaard, Berit. 2013. "Phenomenal Seemings and Sensible Dogmatism." In Seemings and Justification: New Essays on Dogmatism and Phenomenal Conservatism, edited by Chris Tucker, 270-90. Oxford University Press.

Chalmers, David. 2011. "The Nature of Epistemic Space.” In Epistemic Modality, edited by Andy Egan and Brian Weatherson, 60-107. Oxford University Press.

Chudnoff, Elijah. 2013. Intuition. Oxford University Press.

Feldman, Richard. 2003. Epistemology. Prentice Hall.

Feldman, Richard, and Earl Conee. 1985. "Evidentialism." Philosophical Studies 48 (1): 15-34.

Harman, Gilbert. 1986. Change in View. MIT Press.

Hasan, Ali. 2013. "Phenomenal Conservatism, Classical Foundationalism, and Internalist Justification." Philosophical Studies 162 (2): 119-141.

Hawthorne, John, and Lasonen Aarnio, Maria. Manuscript. "Not So Phenomenal!"

Huemer, Michael. 1999. “The Problem of Memory Knowledge.” Pacific Philosophical Quarterly 80 (4): 346-357.

- 2001. Skepticism and the Veil of Perception. Rowman and Littlefield.

- 2006. "Phenomenal Conservatism and the Internalist Intuition." American Philosophical Quarterly 43 (2): 147-58.

—. 2011. "The Puzzle of Metacoherence." Philosophy and Phenomenological Research 82 (1): $1-21$.

—. 2016. "Inferential Appearances." In Intellectual Assurance: Essays on Traditional Epistemic Internalism, edited by Coppenger, Brett and Bergmann, Michael, 144-60. Oxford University Press.

- 2018. "A Probabilistic Critique of Evidentialism." In Believing in Accordance with the Evidence: New Essays on Evidentialism, edited by Kevin McCain, 199-222. Springer.

McGee, Vann. 1985. “A Counterexample to Modus Ponens.” Journal of Philosophy 82 (9): 462471.

McGrath, Matthew. 2007. "Memory and Epistemic Conservatism.” Synthese 157 (1): 1-24.

Peacocke, Christopher. 1992. A Study of Concepts. MIT Press.

Shoemaker, Sydney. 1996. The First-Person Perspective and Other Essays. Cambridge University Press.

Siegel, Susanna, and Alex Byrne. 2017. "Rich or Thin?" In Current Controversies in Philosophy of Perception, edited by Bence Nanay. Routledge.

Smithies, Declan. 2019. The Epistemic Role of Consciousness. Oxford University Press.

Stoljar, Daniel. 2018. "The Regress Objection to Reflexive Theories of Consciousness." Analytic Philosophy 59 (3): 293-308.

Tucker, Chris. 2010. "Why Open-Minded People Should Endorse Dogmatism." Philosophical Perspectives 24 (1): 529-545.

Williamson, Timothy. 2000. Knowledge and Its Limits. Oxford University Press. 